\title{
Factors affecting implementation of green marketing orientation
}

\author{
Neringa Vilkaite-Vaitone ${ }^{1, *}$, and Ilona Skackauskiene $^{2}$ \\ ${ }^{1}$ Vilnius Gediminas Technical University, Faculty of Business Management, Management \\ Department, Sauletekio av. 11, LT-10223, Vilnius, Lithuania \\ ${ }^{2}$ Vilnius Gediminas Technical University, Faculty of Business Management, Management \\ Department, Sauletekio av. 11, LT-10223, Vilnius, Lithuania
}

\begin{abstract}
Traditional marketing is no longer able to address all the issues in modern markets. Global economic crisis, post-Brexit challenges, and changes in the landscape of corporate social responsibility are pushing marketing managers to build sustainability into the performance of the marketing mix. This leads to the development of new marketing philosophy, i. e. green marketing. Companies that implement green marketing orientation send a message to the stakeholders that they care about the society and the ecosystem. While past studies provide useful theoretical insight into the concept and benefits of green marketing decisions, a lack of holistic viewpoint to the factors that determine the choice of green marketing orientation in modern organizations exists. This lack stimulated authors of the paper to address the demand for an integrated analysis of green marketing factors. The article provides researchers and marketing managers with a comprehensive view to the factors affecting the choice of green marketing orientation. Theoretical analysis has shown that factors determining the choice of green marketing orientation can be of external or internal nature. Apart from that, all the factors are direct or indirect and differ in their manageability. The findings of the research present opportunities for researchers and managers to apply green marketing orientation. The article includes directions for future research and managerial implications.
\end{abstract}

\section{Introduction}

Global economic crisis, post-Brexit challenges, changes in the landscape of corporate social responsibility are pushing managers to build sustainability into the performance of marketing mix. This led to green marketing, a new marketing philosophy that is entitled as one of the major trends in modern business [1]. Companies that implement green marketing orientation send a message to the stakeholders that they care about the society and ecosystem. During the past two decades, the importance of the concept of green marketing has been growing exponentially. This concept has become an imperative for minimizing

\footnotetext{
*Corresponding author: neringa.vilkaite-vaitone@vgtu.lt
} 
environmental impact in tourism [2, 3, 4, 5], cosmetics [6], food [7, 8, 9] industries. While past studies provide useful theoretical insights into the concept and benefits of green marketing decisions $[5,7,9,10,11,12,13]$, there exists a lack of holistic viewpoint to the factors that determine the choice of green marketing orientation in modern organizations. The paper addresses the demand for an integrated analysis of green marketing factors.

The main aim of this study is to investigate factors affecting green marketing providing organizations with essential insights into the possible impacts of these factors. To support this aim, the study addresses the following objectives:

1. To examine the concept of green marketing.

2. To find out factors determining a company's choice to adopt green marketing.

3. To suggest the set of green marketing factors based on their impact and manageability.

To achieve the objectives stated above, secondary data has been collected and analysed. Research process started with an extensive search of articles in academic databases. The critical analysis of secondary information and its synthesis provided a base for composing a set of factors affecting green marketing.

\section{Concept of green marketing}

The concept of green marketing dates back to the late 1960s. Since then different terminologies (ecological marketing, environmental marketing, sustainable marketing, enviropreneurial marketing, etc.) and various definitions used in this field leaded to misconception of green marketing associating it phenomenally on distinct characteristics of products, for example, recyclable, refillable, fuel efficient, less polluting, biodegradable. S. K. Jain and G. Kaur [14] suggest defining green marketing as marketing activities undertaken by companies with an objective to strengthen a positive impact or lessen a negative impact of products upon the environment. However, previous research of authors in the field of green marketing [15] incited to define green marketing as organization's engagement in strategic, tactical, and operational marketing activities and processes that have a holistic aim to create, communicate and deliver products with the minimal environmental impact. Such a conceptualization is applicable for various contexts, products, therefore, for the purpose of the article this definition will be used. This definition illustrates that green marketing composes a variety of activities from strategic to operational decisions.

\section{The set of green marketing factors}

Scientific literature analysis $[2,3,9,10,11,12,14,16,17,18,19,20,21,22,23,24,25]$ in the field of green marketing results in many contradictory views of the factors determining adoption of green marketing. Based on these views, authors of the article have prepared a list of factors determining organization's orientation towards green marketing (Table 1). Factors of green marketing are of distinct nature. Probably they also differ in coverage, level or even in intensity. Therefore, the analysis of possible classifications of green marketing factors becomes a must. Y. Shi and Y. Yang [20] suggest classifying green marketing factors into three dimensions: marketing, organization, and environment. According to authors, marketing factors include every element of marketing complex. Organizational factors consist of scale of organization (small, medium or large), support of senior executives, and culture of organization. Competitive pressure, will of partners and government legislation belong to the group of environmental factors. 
Table 1. The list of factors of green marketing

\begin{tabular}{|l|l|}
\hline \multicolumn{1}{|c|}{ Factors } & \multicolumn{1}{|c|}{ Author(s) } \\
\hline $\begin{array}{l}\text { Internal practices of an organization (green } \\
\text { environmental processes, green supplier selection, } \\
\text { green research and development, green resources) }\end{array}$ & C. D'Souza et al. [24] \\
\hline Marketing complex (product, price, place, promotion) & Y. Shi, Y. Yang [20] \\
\hline Scale of organization & Y. Shi, Y. Yang [20] \\
\hline Support of senior executives & $\begin{array}{l}\text { Y. Shi, Y. Yang [20], A. Mahamuni, M. } \\
\text { Tambe [21] }\end{array}$ \\
\hline Culture of organization & Y. Shi, Y. Yang [20] \\
\hline Competitive pressure & $\begin{array}{l}\text { M. J. Polonsky [16], Y. Shi, Y. Yang [20], } \\
\text { E. S. W. Chan [3] }\end{array}$ \\
\hline Will of partners to participate in green activities & Y. Shi, Y. Yang [20] \\
\hline Government legislation & $\begin{array}{l}\text { M. J. Polonsky [16], M. J. Baker [18], S. } \\
\text { K. Jain, G. Kaur [14], Y. Shi, Y. Yang } \\
\text { [20], E. S. W. Chan [3], A. Mahamuni, M. } \\
\text { Tambe [21], P. Mishra, P. Sharma [22], P. } \\
\text { Talebi et al. [25] }\end{array}$ \\
\hline Government support & M. J. Baker [18], P. Talebi et al. [25] \\
\hline $\begin{array}{l}\text { Employees pressure for environmentally friendly } \\
\text { policies }\end{array}$ & S. K. Jain, G. Kaur [14] \\
\hline $\begin{array}{l}\text { Marketers' demographic profile (age, gender, } \\
\text { education) }\end{array}$ & M. E. Dief, X. Font [2] \\
\hline $\begin{array}{l}\text { Customers' demographic profile (age, gender, income, } \\
\text { education) }\end{array}$ & $\begin{array}{l}\text { E. Rex, H. Baumann [19], B. K. Alharthey } \\
\text { [11], L. Baktash, M. A. Talib [12], H. V. } \\
\text { Nguyen et al. [25] }\end{array}$ \\
\hline $\begin{array}{l}\text { Customers' psychographic profile (religiousness, } \\
\text { political orientation, environmental concerns) }\end{array}$ & $\begin{array}{l}\text { E. Rex, H. Baumann [19], D. Arli, F. } \\
\text { Tjiptono [10], H. V. Nguyen et al. [25] }\end{array}$ \\
\hline $\begin{array}{l}\text { Customers' intentions to buy environmentally friendly } \\
\text { products }\end{array}$ & $\begin{array}{l}\text { S. P. Kalafatis et al. [17], S. K. Jain, G. } \\
\text { Kaur [14], D. Arli et al. [23] }\end{array}$ \\
\hline Media exposure of environmental problems & M. J. Baker [18], K. Jain, G. Kaur [14] \\
\hline Species extinction & S. K. Jain, G. Kaur [14] \\
\hline & \\
\hline
\end{tabular}

According to Table 1 the list of green marketing factors is much longer, so every group of factors demand extensions (Table 2). The factors might also be fractionally regrouped, $\mathrm{i}$. e. to internal and external ones.

Table 2. Marketing, organizational and environmental factors of green marketing

\begin{tabular}{|c|l|l|l|}
\hline \multirow{2}{*}{$\begin{array}{c}\text { Type of } \\
\text { factors }\end{array}$} & \multicolumn{2}{|c|}{ Internal } & \multicolumn{1}{c|}{ External } \\
\cline { 2 - 4 } & Marketing & \multicolumn{1}{|c|}{ Organizational } & \multicolumn{1}{c|}{ Environmental } \\
\hline $\begin{array}{l}\text { Elements of } \\
\text { marketing } \\
\text { complex; } \\
\text { marketers; } \\
\text { demographic } \\
\text { profile }\end{array}$ & $\begin{array}{l}\text { Scale of an organization; } \\
\text { support of senior } \\
\text { executives; culture of an } \\
\text { organization; internal } \\
\text { practices of organization; } \\
\text { employees pressure for } \\
\text { environmentally friendly } \\
\text { policies }\end{array}$ & $\begin{array}{l}\text { Competitive pressure; will of partners } \\
\text { to participate in green activities; } \\
\text { government legislation; government } \\
\text { support; customers' demographic } \\
\text { profile; customers' psychographic } \\
\text { profile; customers' intentions to buy } \\
\text { environmentally friendly products; } \\
\text { media exposure of environmental } \\
\text { problems; species extinction }\end{array}$ \\
\hline
\end{tabular}


One more approach to the classification of green marketing factors is based on stakeholders. Attribution of every factor to particular stakeholder is important in finding out the sources of the impacts upon green marketing initiatives. Authors suggest assorting factors to the following stakeholders: shareholders, managers, employees, customers, media, government, competitors, partners and society (Table 3). Pressures from distinct stakeholders result in the companies' intensifying the effort of greener marketing.

Table 3. Classification of green marketing factors based on stakeholders

\begin{tabular}{|l|l|}
\hline Stakeholders & \multicolumn{1}{c|}{ Factors } \\
\hline Shareholders & Scale of an organization; culture of an organization \\
\hline Managers & $\begin{array}{l}\text { Internal practices of an organization; marketing complex; support of senior } \\
\text { executives; marketers' demographic profile }\end{array}$ \\
\hline Employees & Employees pressure for environmentally friendly policies \\
\hline Customers & $\begin{array}{l}\text { Customers' demographic profile; customers' psychographic profile; customers' } \\
\text { intentions to buy environmentally friendly products }\end{array}$ \\
\hline Media & Media exposure of environmental problems \\
\hline Government & Government legislation; government support \\
\hline Competitors & Competitive pressure \\
\hline Partners & Will of partners to participate in green activities \\
\hline Society & Species extinction \\
\hline
\end{tabular}

Authors presume that some factors have direct while others have indirect impact upon company's decision to initiate green marketing. The suggested set of factors and their probable impacts on green marketing are presented in Figure 1.

Indirect factors

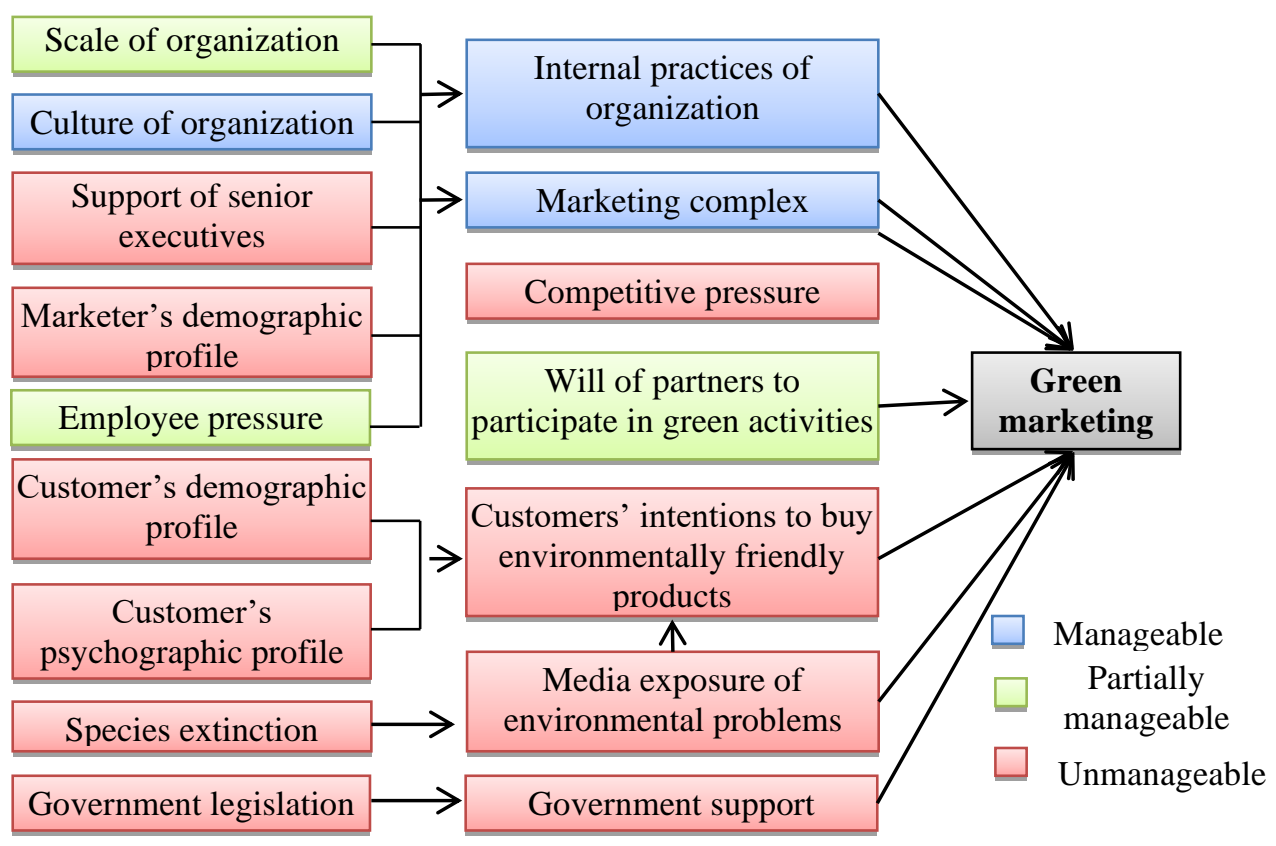

Fig. 1. Green marketing factors, their interrelationships and manageability. 
Majority of direct factors are determined by indirect ones. For example, internal practices of organization and marketing complex might differ depending on the scale and culture of organization, support of senior executives, marketer's demographic profile and employee pressure. Competitive pressure and will of partners to participate in green activities are of direct nature and probably are not formed by indirect factors in the context of green marketing orientation.

According to D'Souza et al. [24] four key internal practices have impact upon application of green marketing, i. e. green environmental processes, green supplier selection, green research and development, green resources. Environmental processes include adoption of cleaner manufacturing processes, company's efforts in environmental planning, assessment, implementation. Green supplier selection involves company's efforts in the field of green procurement planning. D'Souza et al [24] suggest to ground green supplier selection upon the following elements: owing of green resources; green strategies for internal and external operations; green decision making in the fields of product design, purchasing, manufacturing; activities, such as labelling, monitoring, training; design of logistics function. Green research and development lead companies to innovations in green product development and life cycle evaluation. Resource management involves energy sources and waste outputs. In a broader perspective environmental resource management includes company's internal efforts, such as green product design, waste minimization, technological cooperation [24].

Marketing complex usually involves four marketing elements (4P), i. e. product, price, place and promotion [20, 24]. Based on the greenness of each element organization forms green marketing strategy.

Internal practices and marketing complex are determined by five indirect factors. Regarding the strengthening of ecological consciousness of employees [14] one can notice employee pressure for environmentally friendly policies. This pressure is supposed to have influence upon internal practices of organization and marketing complex which were found to have a direct impact on green marketing adoption in the company. Marketer's demographic profile, especially age, gender and academic subject studied is also a serious predictor of internal practices and marketing complex in organization [2]. The other indirect factors that might operate on internal practices and marketing complex are scale of organization, culture of organization and support of senior executives [20, 21].

The desire to maintain a competitive position is a serious motive for green marketing option. In some cases companies face competitors promoting their environmental behaviour and find it as an imperative to emulate this behaviour. Sometimes a competitive pressure even causes the entire industry to change environmental behaviour $[3,16,20]$.

Partner pressure might also stimulate organization to adopt green marketing [20]. This pressure might be related to partners' participation in green activities. Such participation forms a will to stimulate other participants of supply chain to become greener.

Customers' intentions to buy environmentally friendly products have a direct impact upon green marketing decisions in organization [14, 17, 23]. Customers are realizing the consequences of their current behaviour for the future generations, so it is unsurprising that a customer changes a brand to another based on company's environmental attitude. Marketing literature $[11,12,19,25]$ recognizes that demographic characteristics play a significant role in intentions to buy environmentally friendly products. E. Rex and $\mathrm{H}$. Baumann [19] found that young females and people with a relatively high income and education are most likely to engage in green behaviour. Such a finding lets to identify age, gender, income and education as important factors that might encourage customer to choose a greener organization. Psychographic characteristics of customers' have impact as well. E. Rex and H. Baumann [19] identified customers' political orientation and environmental concerns as significant predictors of green marketing initiatives. Study of D. Arli and F. 
Tjiptono [10] have found out that "religiousness has a positive impact on proenvironmental identity, attitudes towards environmental issues".

Government institutions are forcing organizations to become more socially responsible in order to protect customers and society $[3,14,16,18,21,22]$. For example, governments provide legal regulation for the control of waste, issue environmental licenses [25]. Such regulation intends to protect customers and society. Governments in many countries have introduced climate change levies, landfill taxes, product-specific taxes in order to encourage changes in customer behaviour [18]. Government legislation is treated as a base that determines the level of government support towards green initiatives.

A considerable amount of media output is devoted to environmentally related messages $[14,18]$. Some of them emphasize species extinction [14]. Media exposure of environmental problems helps in realizing the organizational impact upon environment. Media also plays a significant role in helping customers' to realize what effect consumption has around the globe. In such a way media and its' exposure of environmental problems not only directly impacts organizational attitude to environmental issues, but also forms and develops customers' intentions to choose environmentally friendly products and sellers, manufacturers and(or) service providers.

Organizations can manage only particular factors of green marketing. Culture of organization, internal practices of organization and marketing complex are identified as fully manageable. Scale of organization, employee pressure and will of partners to participate in green activities are supposed to be partially manageable, while other factors seem to be controlled by other forces.

The suggested set of green marketing factors should not be taken as a definitive one. Different environmental conditions or distinct business models might form a demand for the inclusion of other factors or exclusion of suggested ones. However, a mix of manageable, partially manageable and unmanageable factors attributed to external or internal environment or even to particular stakeholders becomes a base for further researches in this field.

\section{Conclusions}

This study aimed at investigating factors affecting green marketing providing organizations with essential insights into the possible impacts of these factors. Theoretically, implementation of green marketing is a result of internal and external factors directly or indirectly impacting company's choice to adopt green marketing. Through a literature review we found that organization itself can manage such factors as culture, internal practices and marketing complex. Scale of organization, employee pressure and will of partners to participate in green activities were found to be of partially manageable nature. Remainder factors (support of senior executives, marketer's demographic profile, customers' demographic and psychographic profiles, species extinction, government legislation, competitive pressure, customers' intention to buy environmentally friendly products, media exposure of environmental problems, government support) belong to the group of partially manageable factors. Results differ from previous studies, which typically consider several factors having impact upon decision to adopt green marketing based on literature without considering relations between direct and indirect factors. Our research fills the gap of theory in the field of green marketing factors.

Despite the conceptual nature of the study, its findings should be considered as a preliminary step in understanding factors that determine green marketing. Findings of this research can serve as a reference for companies that are planning to initiate green marketing decisions. Companies will find it valuable in understanding the importance of different stakeholders of green marketing initiatives. Authors hope that the findings can be used as a 
relevant theoretical background for the large-scale empirical research of green marketing that is planned in Lithuania.

This project has received funding from European Social Fund (project No 09.3.3-LMT-K-712-020116) under grant agreement with the Research Council of Lithuania (LMTLT).

\section{References}

1. C. Gurau, A. Ranchhod, International green marketing: a comparative study of British and Romanian firms. International Marketing Review 22, 5 (2005)

2. M. E. Dief, X. Font, The determinants of hotels' marketing managers' green marketing behavior. Journal of Sustainable Tourism 18, 2 (2010)

3. E. S. W. Chan, Managing green marketing: Hong Kong hotel managers' perspective. International Journal of Hospitality Management 34 (2013)

4. C. Chandran, P. Bhattacharya, Hotel's best practices as strategic drivers for environmental sustainability and green marketing. Journal of Global Scholars of Marketing Science 29, 2 (2019)

5. Nurjannah, Darmanto, Solimun, A. B. Astuti, A. A. R. Fernandes, L. Amaliana, I. Yanti, R. Isaskar, R., Two step cluster analysis for tourist segmentation coastal object for green marketing strategy. IOP Conference Series: Earth and Environmental Science 239 (2019)

6. L. M. Johri, K. Sahasakmontri, Green marketing of cosmetics and toiletries in Thailand. Journal of Consumer Marketing 15, 3 (1998)

7. M. Canavari, S. Coderoni, Green marketing strategies in the dairy sector: consumerstated preferences for carbon footprint labels. Strategic Change 28 (2019)

8. U. Maruyama, M. V. B. Quintanilha, C. M. S. Silva, P. M. Sanchez, Sustainability and green marketing challenge: Brazilian brewing industry case study. Brazilian Journal of Operations \& Production Management 16 (2019)

9. H. V. Nguyen, N. Nguyen, B. K. Nguyen, A. Lobo, P. A. Vu, Organic food purchases in an emerging market: the influence of consumers' personal factors and green marketing practices of food stores. International Journal of Environmental Research and Public Health 16, 1037 (2019)

10. D. Arli, F. Tjiptono, God and green: investigating the impact of religiousness on green marketing. International Journal of Nonprofit \& Voluntary 22 (2017)

11. B. K. Alharthey, Impact of green marketing practices on consumer purchase intention and buying decision with demographic characteristics as moderator. International Journal of Advanced and Applied Sciences 6, 3 (2019)

12. L. Baktash, M. A. Talib, Green marketing strategies: exploring intrinsic and extrinsic factors towards green customers' loyalty. Quality. Access to Success 20, 168 (2019)

13. K. C. Chang, C. L. Hsu, M. C. Chen, How green marketing, perceived motives and incentives influence behavioural intentions. Journal of Retailing and Consumer Services 49 (2019)

14. S. K. Jain, G. Kaur, Green marketing: an attitudinal and behavioural analysis of Indian consumers. Global Business Review 5, 2 (2004)

15. N. Vilkaite-Vaitone, I. Skackauskiene, Green marketing orientation: evolution, conceptualization and potential benefits. Open Economics 2 (2019) 
16. M. J. Polonsky, An introduction to green marketing. Electronic Green Journal 1, 2 (1994)

17. S. P. Kalafatis, M. Pollard, R. East, M. H. Tsogas, Green marketing and Ajzen's theory of planned behaviour: a cross-market examination. Journal of Consumer Marketing 16, 5 (1999)

18. M. J. Baker, The Marketing Book (Butterworth-Heinemann, Oxford, 2003)

19. E. Rex, H. Baumann, Beyond ecolabels: what green marketing can learn from conventional marketing. Journal of Cleaner Production 15 (2007)

20. Y. Shi, Y. Yang, Critical factors to green marketing strategies implementation of Chinese enterprises. Journal of Marketing Development and Competitiveness, 12, 2 (2008)

21. A. Mahamuni, M. Tambe, Green marketing in automobile and ancillary industry: issues and implications. Journal of Commerce \& Management Thought 5-3 (2014)

22. P. Mishra, P. Sharma, Green marketing: challenges and opportunities for business. BVIMR Management Edge 7(1) (2014)

23. D. Arli, L. P. Tan, F. Tjiptono, L. Yang, Exploring consumers' purchase intention towards green products in an emerging market: the role of consumers' perceived readiness. International Journal of Consumer Studies 42 (2018)

24. C. D‘Souza, M. Taghian, G. Sullivan-Mort, A. Gilmore, An evaluation of the role of green marketing and a firm's internal practices for environmental sustainability. Journal of Strategic Marketing 23, 7 (2015)

25. P. Talebi, N. A. M. Omidi, F. Lashgarara, Designing a green marketing behavioural pattern focusing on poultry products. Applied Ecology and Environmental Research 16, 5 (2018) 